\title{
2007/10
}

Market games and successive oligopolies

Jean J. Gabszewicz, Didier Laussel,

Tanguy van Ypersele and Skerdilajda Zanaj 


\title{
CORE DISCUSSION PAPER $2007 / 10$
}

\section{Market games and successive oligopolies}

\author{
Jean J. GABSZEWICZ ${ }^{1}$, Didier LAUSSEL ${ }^{2}$, \\ Tanguy VAN YPERSELE ${ }^{3}$ and Skerdilajda ZANAJ ${ }^{4}$
}

February 2007

\begin{abstract}
This paper first introduces an approach relying on market games to examine how successive oligopolies do operate between downstream and upstream markets. This approach is then compared with the traditional analysis of oligopolistic interaction in successive markets. The market outcomes resulting from the two approaches are analysed under different technological regimes, decreasing $v s$ constant returns.
\end{abstract}

Keywords: successive oligopolies, market games, entry, double marginalization

JEL classification: D43, L1, L13, L22

${ }^{1}$ CORE, Université catholique de Louvain, Belgium. E-mail: gabszewicz@core.ucl.ac.be ${ }^{2}$ GREQAM, Université de la Méditerranée, France.

${ }^{3}$ GREQAM, Université de la Méditerranée, France.

${ }^{4}$ CORE, Université catholique de Louvain, Belgium and Universita di Siena, Italy. E-mail: zanaj@core.ucl.ac.be

This paper presents research results of the Belgian Program on Interuniversity Poles of Attraction initiated by the Belgian State, Prime Minister's Office, Science Policy Programming. The scientific responsibility is assumed by the authors. 


\section{Introduction}

In the traditional theory of successive markets, the property of double marginalisation has attracted the interest of scholars since its very discovery by Spengler in 1950 (Spengler, 1950). This property says that, when the supply chain is monopolised in each of the successive markets, the price of the final product embodies the monopoly unit margins arising in each of them. This theory is cast assuming that firms, while behaving as monopolists in their own output market, behave as price takers when buying their input. This assumption implies a specific sequentiality in the firms'decisions: in the second stage, the downstream monopolist selects the output level, conditional on the input price. This choice generates a demand function for the input. The effective input price then obtains in the first stage from the equality between the downstream monopolist' s demand and the upstream monopolist's input supply decision. This supply decision is assumed to maximise the upstream monopolist's profit on the demand function of the downstream monopolist, while taking the price of his/her own input as given. This constitutes the traditional approach to present the property of double marginalisation in the bilateral monopoly framework.

This approach has also been recently adopted by Gabszewicz and Zanaj (2006) (henceforth G-Z) in their endeavor to analyse this property in the more general framework of successive oligopolies. In the above paper, the authors consider two successive markets embodying $n$ and $m$ firms, respectively. Firms in these markets select non cooperatively "à la Cournot" the quantities of output of the good they produce, the output of the $m$ upstream firms serving as input for the $n$ downstream ones in the production of their own output. The link between the two markets follows from the fact that the downstream firms' unit cost appears as the unit revenue for the upstream ones: the price paid for a unit of input for the firms in the former constitutes the unit receipt for the firms in the latter. In order to better understand how the effects of entry in successive markets depend on the input-transforming technology, the authors propose a model which makes explicit how the downstream and upstream markets are linked to each other via the production function used by the downstream firms to transform the input into the output. They also investigate entry of new firms, when entry obtains by expanding the economy. In particular, they highlight through prototype examples the differentiated effects of entry corresponding to a constant, or decreasing returns, technology. They show for instance that, under decreasing returns, free entry in both markets does not entail the usual tendency for the input price to adjust to its marginal cost, while it does under constant returns. Again, this analysis is pursued along the traditional assumption that firms, while behaving as oligopolists in their own output market, behave as price takers when buying their input.

The present paper first introduces an alternative approach to examine how successive oligopolies do operate between downstream and upstream markets. This alternative approach relies on the notion of strategic market game $e^{1}$, and

\footnotetext{
${ }^{1}$ see, for instance, Shapley (1977, Shapley and Shubik (1977)) or Dubey and Shubik 1977).
} 
proposes the following timing of firms' decisions. In the second stage, the $n$ downstream oligopolists play a Cournot game in the downstream market, and bid each a quantity of money he/she is willing to offer to get a share of the total input supplied by the $m$ upstream firms in the first stage. This choice generates an amount of money to be shared among the upstream oligopolists in proportion to their input production. In the first stage, the upstream oligopolists choose non cooperatively the amount of input they supply, in order to maximize the amount of money obtained from their input sales. The two approaches essentially differ by the fact that, in the latter, the input price does not obtain through the market clearing condition while it does in the former. Here, the input price, expressed in monetary units, is equal to the ratio between the total amount of bids offered by the downstream firms, and the total amount of input supplied by the upstream ones. As discovered below, this approach leads to different market outcomes than those observed in the traditional approach, when successive oligopolies operate through the usual price mechanism, as in Gabszewicz and Zanaj (2006). Consequently, it naturally invites to contrast the differences between the regime resulting from the just described market game approach, -we call it the market game regime- and the regime analysed in the latter paper, which relies on the traditional theory of successive markets; we call the latter the market regime. In particular, it invites to compare the size of the double marginalisation resulting from each of these alternative regimes.

In the prototype examples considered here and in the above G- $Z$ paper, the comparison between the two regimes leads to the following conclusions: (i) the two regimes generate different market outcomes, with a different double marginalisation under the market game and the market regimes; (ii) even if the market outcomes are different, the two regimes converge to the same outcome under unlimited entry in the input sector, both in the case of decreasing and constant returns; (iii) as in the traditional theory, and in spite of different outcomes, the market game approach does not prevent that, under decreasing returns, free entry in both markets also entails that the usual tendency for the input price to adjust to its marginal cost no longer holds, while it still does under constant returns.

It is a matter of taste to decide which of the two approaches is the most appropriate. The traditional approach, introduced by Spengler (1950), benefits from its repeated use in the analysis of vertical collusive agreements (see, for instance, Salinger (1988) and Gaudet and Van Long (1996), Ordover et al (1990), or in Gabszewicz and Zanaj (2006)). The strategic market game approach offers the advantage of discarding the awkward assumption, implicit in the traditional analysis, that an auctioneer has to choose the upstream market clearing price. In both cases, a sequentiality is introduced in the decisions of the oligopolists. In the former, upstream oligopolists play the first, using for evaluating their payoff the input price resulting from the equality of their total supply with the input demands of the downstream oligopolists. In the latter procedure, upstream oligopolists are also the first to play, but now they use the bids selected by the downstream firms in the second stage game for guiding their decisions. Finally, the present paper shows that the two regimes, while being different for 
a small number of firms and built on different assumptions, lead generally to similar results when the economy expands through entry, and even coincide at the limit.

\section{The model}

We consider two markets, the downstream and upstream markets, with $n$ downstream firms $i, i=1, \ldots n$, in the first producing the output, and $m$ upstream firms $j, j=1, \ldots m$, in the second, producing the input, and selling it in exchange of money . The $n$ downstream firms face a demand function $\pi(Q)$ in the downstream market, with $Q$ denoting aggregate output. Firm $i$ owns technology $f_{i}(z)$ to produce the output, with $z$ denoting the quantity of the sole input used in the production process. The $m$ upstream firms each produce the input $z$ at a total $\operatorname{cost} C_{j}(z), j=1, . ., m$.

We assume that this situation gives rise to a two stage sequential game. In the first stage, the active players are the $m$ upstream firms with input supply strategies $s_{j}$. They aim at maximizing the amount of money they obtain from their input sales. The players in the second stage game are the $n$ downstream firms with money bidding strategies $b_{i}$. They aim at maximizing their profit by obtaining through their bids the quantity of input required to produce their Cournot equilibrium quantity in the downstream market. The two markets are linked to each other via the production function $f_{i}$, namely,

$$
f_{i}\left(z_{i}\right)=f_{i}\left(\frac{b_{i} S}{\sum_{k=1}^{n} b_{k}}\right)
$$

where $\frac{b_{i} S}{\sum_{k=1}^{n} b_{k}}$ constitutes the fraction of total input supply $S$, obtained by firm $i$ through its bidding strategy $b_{i}$.

Given a total input supply $S$, the payoff in the second stage game for the $i_{t h}$ firm at the vector of strategies $\left(b_{i}, b_{-i}\right)$ obtains as

$$
\Pi_{i}\left(b_{i}, b_{-i} ; S\right)=\pi\left(f_{i}\left(\frac{b_{i} S}{\sum_{h=1}^{n} b_{h}}\right)+\Sigma_{k \neq i} f_{k}\left(\frac{b_{k} S}{\sum_{h=1}^{n} b_{h}}\right)\right) f_{i}\left(\frac{b_{i} S}{\sum_{h=1}^{n} b_{h}}\right)-b_{i} .
$$

Given these payoffs, and a total supply $S$ in the input market, the best reply, $b_{i}\left(b_{-i}(S)\right)$ of firm $i$ in the second stage game obtains as a solution (whenever it exists) to the problem

$$
\underset{b_{i}}{\operatorname{Max}} \Pi_{i}\left(b_{i}, b_{-i} ; S\right) .
$$

A Nash equilibrium in the second stage game, conditional on a total input supply $S$, is a vector of strategies $\left(b_{1}^{*}(S), \ldots, b_{n}^{*}(S)\right)$ such that, for all $i, b_{i}^{*}(S)=$ $b_{i}\left(b_{-i}^{*}(S)\right)$. 
In the first stage game, upstream firms select their supply strategies $s_{j}$, $j=1, . ., m$. Given a n-tuple of supply strategies $\left(s_{1}, \ldots, s_{j}, . ., s_{m}\right)$ and a vector of downstream firms' bids $\left(b_{1}, \ldots, b_{n}\right)$ in the second stage game, the amount of money received by firm $j$ obtains as

$$
\Gamma_{j}\left(s_{j}, s_{-j}\right)=\frac{\sum_{k=1}^{n} b_{k}}{\sum_{h=1}^{m} s_{h}} s_{j}-C_{j}\left(s_{j}\right)
$$

which constitutes the payoff function of the $j_{t h}$-upstream firm in the first stage game, conditional on the vector of bids $\left(b_{1}, \ldots, b_{n}\right)$ chosen by the downstream firms in the second stage. Denote by $\left(s_{1}^{*}, \ldots, s_{m}^{*}\right)$ a Nash equilibrium in the firststage game, conditional on the vector of bids $\left(b_{1}, \ldots, b_{n}\right)$. A subgame-perfect equilibrium is a $(n+m)$-tuple of strategies $\left(b_{1}^{*}, \ldots, b_{n}^{*} ; s_{1}^{*}, \ldots, s_{m}^{*}\right)$ such that $(i)$ $\left(b_{1}^{*}, \ldots, b_{n}^{*} ; S^{*}\right)$ is a Nash equilibrium conditional on $S^{*}$ in the second-stage game, with $S^{*}=\sum_{h=1}^{m} s_{j}^{*} ;(i i)\left(s_{1}^{*}, \ldots, s_{n}^{*}\right)$ is a Nash equilibrium in the first stage game conditional on the vector of bids $\left(b_{1}^{*}, \ldots, b_{n}^{*}\right)$.

\section{Exploring subgame perfect equilibria}

It is difficult to analyze subgame perfect equilibria at the full level of generality underlying the above model. This is why, as in Gabszewicz and Zanaj (2006), and in view of comparing our analysis with the latter paper, we explore the properties of subgame equilibria by looking at the same two prototype examples. The first corresponds to a situation in which downstream firms are endowed with a decreasing returns technology while the second is characterized by constant returns. Furthermore, we assume in both examples a linear demand function in the downstream market, as in Salinger (1988), Gaudet and Van Long (1996) and Gabszewicz and Zanaj (2006). We also assume that firms operating in the upstream (resp. downstream) market are all identical. Entry and competition are analyzed through the asymptotic properties of the subgame-perfect equilibrium when the number of firms in the markets is increased by expanding the economy, as in Debreu and Scarf (1963). The two examples are now successively considered.

\subsection{Decreasing returns}

The $n$ downstream firms are assumed to face a linear demand $\pi(Q)=1-Q$ in the downstream market. They share the same technology $f(z)$ to produce the output, namely

$$
q=f(z)=z^{\frac{1}{2}} .
$$

The $m$ upstream firms each produce the input $z$ at the same linear total cost $C_{j}\left(s_{j}\right)=\beta s_{j}, j=1, . ., m$.

When the $m$ upstream firms have selected a total amount of input $S=$ $\sum_{h=1}^{n} b_{h}$ in the first stage game, the payoffs of the $i_{t h}$ downstream firm in the second stage game conditional on $S$, at the vector of bidding strategies $\left(b_{i}, b_{-i}\right)$, writes as 


$$
\Pi_{i}\left(b_{i}, b_{-i} ; S\right)=\left(1-\left(\frac{b_{i} S}{b_{i}+B^{\prime}}\right)^{\frac{1}{2}}-\Sigma_{k \neq i}\left(\frac{b_{k} S}{b_{i}+B^{\prime}}\right)^{\frac{1}{2}}\right)\left(\frac{b_{i} S}{b_{i}+B^{\prime}}\right)^{\frac{1}{2}}-b_{i},
$$

with $B^{\prime}=\Sigma_{h \neq i} b_{h}$. Using first order conditions, the symmetric Nash equilibrium in the second stage game conditional on $S$ obtains as

$$
b_{i}^{*}(S)=b^{*}(S)=\frac{(n-1)\left(\sqrt{\frac{S}{n}}-S\right)}{2 n}, i=1, . ., n .
$$

In the first stage, the payoff $\Gamma_{j}$ of the $j_{t h}$ upstream firm at the vector of strategies $\left(s_{j}, s_{-j}\right)$ writes as

$$
\Gamma_{j}\left(s_{j}, s_{-j}\right)=\frac{\sum_{k=1}^{n} b_{k}}{s_{j}+S^{\prime}} s_{j}-\beta s_{j} .
$$

with $S^{\prime}=\Sigma_{h \neq j} s_{h}$ and $S=\Sigma_{h=1}^{n} b_{h}$. At the symmetric subgame perfect equilibrium, we know that

$$
\sum_{k=1}^{n} b_{k}=n b^{*}(S)=\frac{(n-1)\left(\sqrt{\frac{S}{n}}-S\right)}{2} .
$$

Plugging this expression in the payoff $\Gamma_{j}\left(s_{j}, s_{-j}\right)$, we get

$$
\Gamma_{j}\left(s_{j}, s_{-j}\right)=\frac{(n-1)\left(\sqrt{\frac{s_{j}+S^{\prime}}{n}}-\left(S^{\prime}+s_{j}\right)\right.}{2\left(s_{j}+S^{\prime}\right)} s_{j}-\beta s_{j} .
$$

From the first-order necessary and sufficient conditions and symmetry, we get that

$$
s_{j}^{*}=s^{*}=\frac{(2 m-1)^{2}(n-1)^{2}}{4 n m^{3}(2 \beta+n-1)^{2}}, j=1, . ., m,
$$

which constitutes the individual supply of input by each upstream firm at the subgame perfect equilibrium.

Substituting this value in $b^{*}\left(S^{*}\right)$, with $S^{*}=m s^{*}$, we get

$$
b^{*}\left(S^{*}\right)=\frac{(n-1)^{2}(2 m-1)(4 m \beta+n-1)}{8 n^{2} m^{2}(2 \beta+n-1)^{2}},
$$

which is the bidding strategy played by each downstream firm at the Nash equilibrium conditional on $S^{*}=m s^{*}$ in the second stage game. Acccordingly, the $(n+m)$-vector $\left(b^{*}\left(S^{*}\right), . ., b^{*}\left(S^{*}\right) ; s^{*}, . ., s^{*}\right)$ constitutes, under decreasing returns, the symmetric subgame perfect equilibrium of the sequential game.

In order to compare the double marginalisation arising at the subgame perfect equilibrium described above, with the one arising in the G-Z-paper, we compute the output price in the downstream market resulting from the 
symmetric subgame equilibrium we have just identified. At this equilibrium, the level of production of each downstream firm is equal to $\left(\frac{b_{i} S}{b_{i}+B^{\prime}}\right)^{\frac{1}{2}}$ with $b_{i}=b^{*}\left(S^{*}\right), B^{\prime}=(n-1) b^{*}\left(S^{*}\right)$ and $S=S^{*}=m s^{*}$, namely, $\sqrt{\frac{(n-1)^{2}(2 m-1)^{2}}{4 n^{2} m^{2}(2 \beta+n-1)^{2}}}$, or $\frac{(n-1)(2 m-1)}{2 n m(2 \beta+n-1)}$. Substituting this value in the demand function $\pi(Q)=1-Q$, we get the output price $\pi^{*}$ corresponding to the subgame perfect equilibrium, namely,

$$
\pi^{*}=\frac{4 m \beta+n-1}{2 m(2 \beta+n-1)}
$$

A direct comparison between $\pi^{*}$ and the output price obtained at equilibrium in G-Z, namely, $\frac{4 m \beta+n-1}{2(2 m-1)}$, shows that

Proposition 1 Under decreasing returns, the double marginalisation observed in the mqrket mechanism model of successive oligopolies exceeds the one arising at the symmetric subgame perfect equilibrium in the market game model.

A surprising outcome obtained at equilibrium in the traditional model is that, under decreasing returns, when both the number of upstream and downstream firms tend simultaneously and in the same proportion to infinity, the equilibrium input price does not converge to the upstream firms' marginal cost, but exceeds it by an amount which decreases with the ratio of the number of firms in each market $\left(\frac{n}{m}\right)$. In the market game model, the counterpart of the input price is the ratio $\frac{\sum_{k=1}^{n} b_{k}}{\sum_{h=1}^{m} s_{h}}$ between the total money bids of downstream firms and the total input supply proposed by the upstream ones. At equilibrium this ratio is equal to $\frac{(4 m \beta+n-1)}{2(2 m-1)}$. Multiplying by $k$ each value of $n$ and $m$ in this expression, we get

$$
p^{*}(k)=\frac{4 k m \beta+k n-1}{4 k m-2},
$$

which does not tend to the input marginal $\operatorname{cost} \beta$ when $k$ tends to infinity. Thus we may state the following

Proposition 2 Under decreasing returns, and as in the market mechanism model, when both the number of upstream and downstream firms tend simultaneously to infinity, the equilibrium input price does not converge to upstream firms' marginal cost, but exceeds it by an amount which decreases with the ratio of the number of firms $\frac{n}{m}$.

Another striking observation revealed in the G-Z analysis is that, under decreasing returns, the profit of the downstream firms does not always increase with the number of upstream firms, in spite of the increase in competition resulting from entry in the upstream market. In particular, it is shown there that, when $n>3$, the profit of a downstream firm always decreases as the number $m$ of upstream firms increases, if the condition

$$
m>\frac{n-1}{n-3}
$$


is satisfied. Substituting the values $b^{*}\left(S^{*}\right)$ and $s^{*}$ in the payoff $\Pi_{i}$ of each downstream firm at equilibrium, it is easily checked that, whatever the positive value of $\beta$, the derivative $\frac{\partial \Pi_{i}}{\partial m}$ is always positive: as intuitively expected, and contrary to the procedure analyzed in $\mathrm{G}-\mathrm{Z}$, more competition in the upstream market here always entails an increase in profit for the downstream firms.

\subsection{Constant returns}

Assume now that downstream firms still face a linear demand $\pi(Q)=1-Q$ but now use a constant returns technology to produce the output:

$$
f(z)=\alpha z, \alpha>0 .
$$

The profits $\Pi_{i}\left(b_{i}, b_{-i} ; S\right)$ of the $i_{t h}$ downstream firm at the vector of strategies $\left(b_{i}, b_{-i}\right)$ and $S$ now obtains as

$$
\Pi_{i}\left(b_{i}, b_{-i} ; S\right)=\left(1-\alpha \frac{b_{i}}{b_{i}+B^{\prime}} S-\alpha \sum_{k \neq i} \frac{b_{k}}{b_{i}+B^{\prime}} S\right) \alpha \frac{b_{i} S}{b_{i}+B^{\prime}}-b_{i}
$$

with $B^{\prime}=\sum_{h \neq i} b_{h}$.

Solving the maximisation problem of a downstream firm and using symmetry, we get at equilibrium

$$
b^{*}(S)=\frac{(1-S \alpha)(n-1) S \alpha}{n^{2}}
$$

Hence, the payoff $\Gamma_{j}$ of an upstream firm at the first stage of the game, after substituting for $b^{*}$,obtains as

$$
\Gamma_{j}\left(s, s_{-j}\right)=\frac{\left(1-\left(s_{j}+S^{\prime}\right) \alpha\right)(n-1)\left(s_{j}+S^{\prime}\right) \alpha}{\left(s_{j}+S^{\prime}\right)} s_{j}-\beta s_{j} .
$$

Maximising $\Gamma_{j}\left(s, s_{-j}\right)$, yields at the symmetric equilibrium

$$
s^{*}=\frac{(n \alpha-\alpha-n \beta)}{(n-1)(m+1) \alpha^{2}} .
$$

Hence the optimal quantity of money $b^{*}\left(S^{*}\right)$ that each downstream firm bids obtains by substituting $s^{*}$ in $b\left(s_{j}, s_{-j}\right)$, namely,

$$
b^{*}\left(S^{*}\right)=\frac{(\alpha-n \alpha-m n \beta)(\alpha-n \alpha+n \beta) m}{\alpha^{2} n^{2}(n-1)(m+1)^{2}} .
$$

As in the previous section, we may calculate the input price as the ratio $\frac{\sum_{k=1}^{n} b_{k}}{\sum_{h=1}^{m} s_{h}}$, and we get

$$
p^{*}=\frac{n(\alpha+m \beta)-\alpha}{\alpha(m+1) n} .
$$


Accordingly, the $(n+m)$-vector $\left(b^{*}\left(S^{*}\right), . ., b^{*}\left(S^{*}\right) ; s^{*}, . ., s^{*}\right)$ constitutes, under constant returns, the symmetric subgame perfect equilibrium of the sequential game.

In order for this vector to be an equilibrium, it is also required that the values $b^{*}\left(S^{*}\right)$ and $s^{*}$ to be both positive. These two inequalities are both simultaneously satisfied if and only if the condition

$$
\alpha \geq \frac{n}{(n-1)} \beta
$$

holds. This condition coincides with the condition which guarantees that both upstream and downstream firms make positive profits. Notice that this condition is slightly stronger than the condition required to be satisfied in the traditional model, which simply boils down to $\alpha \geq \beta$. The reason for this strengthening should be found in the indirect strategic power that downstream firms exert in the upstream market : they influence the amount of input sales via their money bids, and this influence fades away when the number $n$ of downstream firms increases. In the traditional model, this influence does not exist since downstream firms take the input price as given when buying the input ${ }^{2}$.

The two approaches - the market mechanism approach, or the market games approach, - mainly differ according to how downstream firms' total production costs are introduced in the model. In the market mechanism approach, these costs depend on the input price and the quantity of input invested in production. In the market game approach, total costs do not depend on the quantity of input invested in the production, but reduces to a lump-sum amount corresponding to the bid offered by the downstream in exchange of its input share. Nothing prevents to deduce from it a notion of average cost (and marginal cost in the case of constant returns) simply by dividing the bid by the number of output units produced. Using this notion, it easy to show that, when the economy is replicated $k$-times, increasing thereby simultaneously the number of downstream and upstream firms, both the input and output prices converge to their competitive values, $\beta$ and $\frac{\beta}{\alpha}$, respectively. We summarize the above in the following

Proposition 3 Under constant returns and whatever the regime, market or market game, both the input and output prices tend to their competitive counterparts when the economy is replicated at the same speed in the upstream and the downstream markets.

Finally, it is interesting to compare the size of the double marginalisation effect under the two regimes. This can easily be done by directly comparing the equilibrium per downstream firm output production levels into the two regimes. We obtain the following

\footnotetext{
${ }^{2}$ A similar condition appears in another,but close, context (see Gabszewicz and Michel (1997)). These authors analyse the oligopoly equilibrium of a market game with exchange and production.
} 
Proposition 4 Under constant returns, the double marginalisation observed in the market game regime exceeds the one arising at the symmetric subgame perfect equilibrium in the market regime.

Notice the crucial role played by the technology linking the input and the output markets: with constant returns, the double marginalization effect is larger under the market game regime than under the market regime, while the reverse holds under decreasing returns!

\section{Conclusion}

In this paper, we clarify how entry affects successive markets when the technology linking these markets is made explicit and the concept of market game is used to describe the economic outcome of the downstream and upstream firms' interaction. We have differentiated the effects of entry in these markets according to the nature of the technology : constant and decreasing returns, making explicit several properties which differ in each of these cases. Moreover, we have highlighted how double marginalization is influenced by the technology used to produce the output.

Our exploration of industry equilibria departs from the existing literature because it does not start from the assumption of price taking agents in the demand side of the markets. In particular, it does not assume that downstream firms behave as price-takers in the upstream market, an awkward assumption because it is difficult to justify the fact that an economic agent behaves strategically in one market but not in the other. A reasonable treatment thus requires downstream firms behaving strategically simultaneously in the downstream and upstream markets. This is what we provide in this paper since the firms are strategic in both stages of the game, i.e, in the downstream and upstream markets.

\section{References}

[1] Debreu G. and Scarf H., "A Limit Theorem on the Core of an Economy", 1964, International Economic Review, Vol. 4, 235-246.

[2] Gabszewicz J. J. and Michel Ph., "Oligopoly equilibrium in exchange economy" in Trade, technology and economics: Essays in Honour of Richard G. Lipsey, Edited by B. C. Eaton and R. G. Harris, Edward Elgar, Cheltenham, 1997, 217-240.

[3] Gaudet G. and Van Long N., "Vertical Integration, Foreclosure and Profits in the Presence of Double Marginalisation", Journal of Economics and Management Strategy, 1996, Vol. 5(3), 409-432

[4] Ordover, J. and Saloner, G. and Salop, S.: "Equilibrium vertical foreclosure", The American Economic Review, 1990, Vol. 80, 127-142 
[5] Salinger M., "Vertical mergers and market foreclosure", The Quartely Journal of Economics, 1988, Vol. 103, 345-356

[6] Spengler J. J. : " Vertical integration and antitrust policy", Journal of Political Economy,1950, Vol. 58, 347-352 